\title{
Retraction Note to: An improved data mining technique \\ for classification and detection of breast cancer from mammograms
}

\author{
Aswini Kumar Mohanty ${ }^{1} \cdot$ Manas Ranjan Senapati ${ }^{2} \cdot$ Saroj Kumar Lenka $^{3}$
}

Published online: 26 October 2015

(C) The Natural Computing Applications Forum 2015

\section{Retraction Note to: Neural Comput \& Applic (2013) 22 (Suppl 1): S303-S310 \\ DOI 10.1007/s00521-012-0834-4}

The Editor-in-Chief has decided to retract this article. Upon investigation carried out according to the Committee on Publication Ethics guidelines, it has been found that the authors have duplicated substantial parts from the following article:

Development of a computer-aided classification system for cancer detection from digital mammograms

Author(s) Alolfe, M.A.; Dept. of Syst. and Biomed. Eng., Cairo Univ., Cairo; Youssef, A.-B.M.; Kadah, Y.M.; Mohamed, A.S.

Published in: Radio Science Conference, 2008. NRSC 2008. National
Date of Conference: 18-20 March 2008

Page(s): 1-8

DOI: $10.1109 /$ NRSC.2008.4542383

Publisher: IEEE

http://ieeexplore.ieee.org/xpl/articleDetails.jsp?arnumber= 4542383

The online version of the original article can be found under doi:10.1007/s00521-012-0834-4.

Aswini Kumar Mohanty

asw_moh@yahoo.com

Manas Ranjan Senapati

manas_senapati@sify.com

Saroj Kumar Lenka

lenka.sarojkumar@gmail.com

1 SOA University, Bhubaneswar, Orissa, India

2 Department of Computer Science, Krupajal Engineering College, Bhubaneswar 752002, Orissa, India

3 Department of Computer Science, Modi University, Lakshmangarh 332311, Rajasthan, India 